\title{
Selective effect of irreversible electroporation on parenchyma of the pancreas and its vascular structures - an in vivo experiment on a porcine model
}

\author{
Roman Svatoň ${ }^{1}$, Jan Hlavsa ${ }^{1}$, Zdeněk Kala ${ }^{1}$, Vladimír Procházka ${ }^{1}$, Katarína Gašparová ${ }^{1}$, \\ Michal Crha², Alois Nečas², Petr Raušer², Tomáš Andrašina ${ }^{3}$, Vladimír Válek ${ }^{3}$, \\ Iva Svobodová ${ }^{4}$
}

\begin{abstract}
${ }^{1}$ University Hospital and Masaryk University Brno, Department of Surgery, Brno, Czech Republic ${ }^{2}$ University of Veterinary and Pharmaceutical Sciences Brno, Faculty of Veterinary Medicine, Department of Surgery and Orthopedics, Small Animal Clinic, Brno, Czech Republic

${ }^{3}$ University Hospital and Masaryk University Brno, Department of Radiology, Brno, Czech Republic ${ }^{4}$ St. Anne’s University Hospital Brno, Department of Pathology, Brno, Czech Republic
\end{abstract}

Received January 28, 2016

Accepted June 1, 2016

\begin{abstract}
Irreversible electroporation is a local, non-thermal ablation method, where short electrical pulses of high voltage lead to changes in cell membrane permeability and cell death. Recent experimental studies have shown that it does not lead to damage of blood vessels, nerves, bile duct or ureters. The aim of our experimental study was to evaluate the negative effect of irreversible electroporation regarding damage to the vascular wall and porcine pancreatic tissue. Irreversible electroporation of the pancreas was performed in 6 pigs after medial laparotomy. Irreversible electroporation was applied to each pig to the splenic lobe of the pancreas in order to assess damage to the pancreatic tissue and to the duodenal lobe of the pancreas to assess damage to the vascular structure of the pancreatic tissue. Higher ablation electric intensity (minimum $500 \mathrm{~V} / \mathrm{cm}$ - maximum $1,750 \mathrm{~V} / \mathrm{cm}$, step $250 \mathrm{~V} / \mathrm{cm}$ ) in $90 \mu \mathrm{s}$ pulses was utilized on each pig. After 7 days, macroscopic and microscopic evaluations of en bloc resected specimen (pancreas with duodenum) were performed. During 7 post-ablation days, no deaths or clinical worsening occurred in any of the pigs. Necrotic changes in the pancreatic tissue were recorded at an electric intensity of $750 \mathrm{~V} / \mathrm{cm}$. Changes in the outer layers of the wall of the arteries and veins occurred at $1,000 \mathrm{~V} / \mathrm{cm}$. Transmural vascular wall damage was not recorded in any case. Irreversible electroporation allows for relatively efficient cell death in the target tissues. Our independent experimental work confirms the safety of this method towards vascular structures located in the ablation zone.
\end{abstract}

IRE, NanoKnife, ablative methods, vessel, damage

Tumour destructive (ablative) methods are used in cases where the solid tumour cannot be removed with radical resection or by post resection residual tumour tissue treatment. For ablation various physical modalities are used such as the electric current, ultrasound or heat. Irreversible electroporation (IRE) is an ablation method using short electrical pulses ( microseconds) of high voltage. Their effect leads to changes in cell membrane permeability, to the formation of small (nano) pores, and subsequently, to a disorder of cellular homeostasis and apoptosis of exposed cells (Weaver 1995).

Unlike electrothermal ablation methods such as radiofrequency ablation (RFA), microwave ablation and conventional electric heating, during IRE the thermal effect of electricity is applied. The result is also not negatively affected by cooling the blood flow in large vessels situated close to the ablated tissues (heat sink effect). At the same time there should be no damage to the ligament structures of the blood vessels, nerves, bile ducts or ureters. (Rubinsky et al. 2007; Charpentier et al. 2010; Li et al. 2011).

Address for correspondence:

MUDr. Jan Hlavsa, Ph.D.

Department of Surgery

University Hospital and Masaryk University Brno

Jihlavská 20, 62500 Brno, Czech Republic 
Thanks to the preservation of vascular stroma, faster tissue regeneration occurs with less scarring, and a positive cellular immune response at the site of ablation was also reported (Li et al. 2012).

The aim of our independent in vivo experimental study was to evaluate the effect of IRE regarding damage to artery walls and pancreatic tissue in pigs.

\section{Materials and Methods}

We performed an experimental prospective in vivo study on a group of 6 laboratory pigs weighing $35 \pm 2 \mathrm{~kg}$. The experimental project (No. 51-2014) was approved by the expert committee on animal welfare of the University of Veterinary and Pharmaceutical Sciences Brno according to the law on the protection of animals against cruelty, as amended by §17, paragraph $15 \mathrm{~g}$ ), Act no. 246/1992 Coll. The pigs were housed in stone hutches under controlled environmental conditions $\left(20\right.$ to $22{ }^{\circ} \mathrm{C}$ room temperature, $50 \%$ to $60 \%$ relative humidity, $12 \mathrm{~h}$ light and $12 \mathrm{~h}$ dark cycle). Each animal underwent median laparotomy whereby the duodenal and splenic lobe of pancreas was exposed. To perform IRE we used the NanoKnife ${ }^{\circledR}$ device (Plate I, Fig. 1) and unipolar electrodes with a diameter of $1 \mathrm{~mm}$.

Two electrodes were inserted into the pancreas of each pig in the following areas:

1) The duodenal lobe (Plate I, Fig. 2) - the distance between the electrodes was $20 \mathrm{~mm}$, right in the middle between the electrodes were the artery and veins at least $2 \mathrm{~mm}$ in diameter 2) The splenic lobe (Plate I, Fig. 3) - the distance between the electrodes was $20 \mathrm{~mm}$.

We used 90 pulses, each with a duration of $90 \mu$ s and each pig was ablated with higher electric intensity in the steps described in Table 1.see

Table 1. Distribution of electric intensity.

Finally, the abdominal wall was closed in three layers. The whole procedure was carried out under general anaesthesia with deep myorelaxation, and the animals were intubated and artificially ventilated. All pigs were sedated by intramuscular administration of a mixture of tiletamine-zolazepam $(2 \mathrm{mg} / \mathrm{kg}$, Zoletil 100, Virbac, France), xylazine $(0.5 \mathrm{mg} / \mathrm{kg}$, Xylazin $2 \%$, Riemser, Germany) and ketamine ( $2 \mathrm{mg} / \mathrm{kg}$, Narketan, Vetoquinol, France). All substances were administered together in a single syringe. Anaesthesia was induced by intravenous administration of propofol $(1-2 \mathrm{mg} / \mathrm{kg}$, Propofol $1 \%$, Fresenius, Austria) and maintained by continuous intravenous administration of propofol $(0.1-0.3 \mathrm{mg} /$ $\mathrm{kg} / \mathrm{min})$. We used atracrium $(1.5 \mathrm{mg} / \mathrm{kg}$, Tracurium, GlaxoSmithKline, Italy) for myorelaxation. After surgery, the animals were awakened and pain was efficiently controlled by meloxicam $(0,2 \mathrm{mg} / \mathrm{kg}$, Metacam $5 \mathrm{mg} /$ $\mathrm{ml}$, Boehringer Ingelheim, Germany). The animals were euthanized 7 days after surgery. In each pig, an en bloc specimen of pancreas with duodenum was excised. All specimens were fixed in formalin and embedded in paraffin. Histological analysis was performed using acid fuchsin orange (AFOG), Sirius red elastic (SRel) and periodic acid-schiff (PAS) staining and evaluated by one experienced pathologist on the macroscopic and microscopic levels.

\section{Results}

During the seven days after the application of IRE on the porcine pancreas, no death or clinical worsening occurred in any of the six pigs. Depending on the electric field intensity applied, macroscopic and microscopic changes in the blood vessels and pancreatic tissue were observed which are presented in Table 2 and Figs 4a-15 (Plates II-VII).

\section{Discussion}

IRE is a new local electro-ablative, non-thermal method. Short electrical pulses of high voltage affect transmembrane potential, induce instability polarized phospholipid double layer, resulting in the formation of small (nano) pores in the cell membranes. Pore formation is reversible or irreversible (Freeman et al. 1994). 
Table 2. The effect of IRE on the artery, vein, and pancreatic tissue for each electric intensity.

\begin{tabular}{llll}
\hline & Artery & Vein & Pancreatic tissue \\
\hline $\begin{array}{l}\text { Subject I }(500 \mathrm{~V} / \mathrm{cm}) \\
\text { Subject II }(750 \mathrm{~V} / \mathrm{cm}\end{array}$ & $\begin{array}{l}\text { No changes } \\
\text { No changes }\end{array}$ & $\begin{array}{l}\text { No changes } \\
\text { No changes } \\
\text { Mild regressive changes } \\
\text { on the outer half of wall, } \\
\text { Subject III }(1,000 \mathrm{~V} / \mathrm{cm})\end{array}$ & $\begin{array}{l}\text { Regressive changes } \\
\text { on the outer half of wall } \\
\text { Muld recral thrombosis }\end{array}$ \\
Subject IV $(1,250 \mathrm{~V} / \mathrm{cm})$ & No changes & $\begin{array}{l}\text { Mild regressive changes } \\
\text { on the outer half of wall }\end{array}$ & Necrosis \\
Subject V $(1,500 \mathrm{~V} / \mathrm{cm})$ & $\begin{array}{l}\text { Mild regressive changes } \\
\text { on the outer half of wall }\end{array}$ & $\begin{array}{l}\text { Mild regressive changes } \\
\text { on the outer half of wall, } \\
\text { intraluminal thrombosis } \\
\text { Regressive changes } \\
\text { on the outer half of wall }\end{array}$ & Necrosis \\
Subject IV $(1,750 \mathrm{~V} / \mathrm{cm})$ & $\begin{array}{l}\text { Regressive changes } \\
\text { on the outer half of wall }\end{array}$ & Necrosis \\
\hline
\end{tabular}

The effect of the reversible formation of pores (reversible electroporation) is used to facilitate the transport of substances (cytostatic, enzymes, antibodies, DNA, fluorescent or radioactive agents) into the cell (Yao et al. 2013; Teissie 2014).

During irreversible electroporation, permanent defects in cell membranes are generated, which causes the disruption of cellular homeostasis and cell death. Given that, during IRE in contrast with radiofrequency ablation (RFA), microwave ablation or conventional electric heating, the thermal effect of electric current is not applied, and the ablation result is not negatively affected by a possible cooling of the blood flowing in the vessels running near the electrodes (the heat sink effect). At the

Table 3. Thermal ablative methods vs. IRE according to Martin 2015.

\begin{tabular}{lll}
\hline Effect & Thermal ablation & IRE \\
\hline Act of damage & Entire cell & Only cell membrane \\
Protein denaturation & Typical & Not present \\
Blood flow & Effects efficacy ablation & No effect \\
Connective tissue & Damaged & Spared \\
Region damage & Gradual change & Better defined \\
Immunological effect & Present & Present \\
\hline
\end{tabular}
same time, there should be no damage to the ligament structures of blood vessels, nerves, ducts, bronchi or ureters (Maor et al. 2007; Philips et al. 2013; Martin 2015), (see Table 3).

This ablation technique is used in human medicine for the treatment of primary and secondary tumours of the liver, kidney, lung, prostate, pancreas, eyes, and brain. (Phillips et al. 2013). For example, after IRE of local advanced pancreatic adenocarcinoma, an increase was recorded in local progression - free survival (14 vs. 6 months, $P=0.01$ ), distant progression - free survival (15 vs. 9 months, $P=0.02)$, and over all survival ( 20 vs. 13 months, $P=0.03$ ) compared with standard chemoradiotherapy (Martin et al. 2013).

Procedures should be performed under general anaesthesia with deep neuromuscular blockade. During the ablation itself, a different number of uni- or bi-polar electrodes placed into the target tissue is used. Electrodes can be inserted percutaneously with ultrasound or CT navigation, as well as laparoscopically or by open approach, including a combination with resection surgery (Lee et al. 2007; Martin et al. 2015). The range of ablation is dependent on the length of the electrode's active parts $(0.5-4 \mathrm{~cm})$, their mutual distance $(0.5-4 \mathrm{~cm})$, electrical intensity $(1,500-3,000 \mathrm{~V} / \mathrm{cm})$, the number (70 to 90$)$ and the duration of individual electric pulses (70-100 $\mu$ s) (Silk et al. 2014). In our experiment, we used two unipolar electrodes with a diameter of $1 \mathrm{~mm}$ and they were spaced $20 \mathrm{~mm}$. The electric 
intensity of ablation was a gradual increase within the range of $500-1,750 \mathrm{~V} / \mathrm{cm}$ in steps of $250 \mathrm{~V} / \mathrm{cm}$.

Electrodes insertion into ablated tissue may be associated with bleeding, biliary or pancreatic fistula. In the case of the ablation of pancreatic tissue pancreatitis and portal vein thrombosis have been described. The electrical pulses cause muscle contraction; deep myorelaxation is therefore necessary. There is also the risk of cardiac arrhythmias, and the frequency of the electrical pulses must be synchronized with the heart rhythm (Mali et al. 2008). In our in vivo experiment no intraoperative complications, death or clinical deterioration of used animals occurred. It should be noted that only clinical conditions (body temperature, blood pressure, heart rate, saturation, mind, abdominal and wound state) were evaluated. Because it was not the aim of the experiment, paraclinical examinations were not performed.

The IRE ablation is contraindicated in intrathoracic lesions with the presence of a pacemaker or defibrillator, in lesions near the implanted electrical devices or objects with metallic parts, in eye with ocular lens, in patients with recent myocardial infarction, cardiac arrhythmia or epilepsy (Månsson et al. 2014).

Focusing on IRE of the pancreas, the experiments with porcine models demonstrate the efficacy and safety of this method. Particularly interesting is the ability of this method to preserve intact vessels of ligamentous structures (Charpentier et al. 2010; Bower et al. 2011). In agreement with previous experiments, our independent study also did not record transmural vascular disorders. Nevertheless, changes in the outer layers of the wall artery and vein occurred at an electric intensity of $1,000 \mathrm{~V} / \mathrm{cm}$. At the same electric intensity, we also observed intraluminal venous thrombosis. Arterial thrombosis was not observed in our experiment. Necrosis of the pancreatic tissue was recorded from the electric field intensity of $750 \mathrm{~V} / \mathrm{cm}$; i.e. at a lower intensity than for which we recorded the least minimal changes of the outer layers vascular wall.

The question is, whether the tumour cells respond to IRE as well as healthy tissues. Presuming the known resistance of tumour cells to apoptotic phenomena, we expect the need to use higher energies or extension of the number and duration of pulses. This is also not an absolute declaration of the absence of thermal damage with IRE. Based on physical laws, it is known that the passage of electric current through a conductor (electrode) releases at least minimal joule heat. It has been experimentally proven that in cases of high currents, and in combination with a high number of pulses, thermal damage also occurred ( $>270$ pulses and voltage settings $>2,900 \mathrm{~V}$ ) (Faroja et al. 2013; Silk et al. 2014). The behaviour of only partially ablated tumour tissue was also interesting. In an experimental model recurrent tumours had a steeper growth curve (slope $=0.73$ ) compared to primary tumors $(0.60, P=0.02)$ and had a significantly higher percentage of EpCAM expression that could be more resistant to the standard care of chemotherapy (Philips et al. 2015).

In conclusion, the IRE is a new non-thermal, electro-ablative method which allows relatively efficient cell death in the target tissue. As documented in our independent experiments, energies fully sufficient to induce necrosis of the pancreatic tissue do not cause transmural damage of the vascular wall.

\section{Acknowledgements}

This work was supported by the Grant Agency of the Ministry of Health of the Czech Republic (IGA MZ ČR, Project No. NT 14579-3/2013).

\section{References}

Bower M, Sherwood L, Li Y, Martin R 2011: Irreversible electroporation of the pancreas: definitive local therapy without systemic effects. J Surg Oncol 104: 22-28

Faroja M, Ahmed M, Appelbaum L, Ben-David E, Moussa M, Sosna J, Nissenbaum I, Goldberg SN 2013: Irreversible electroporation ablation: is all the damage nonthermal? Radiology 266: 462-470 
Freeman SA, Wang MA, Weaver JC 1994: Theory of electroporation of planar bilayer membranes: predictions of the aqueous area, change in capacitance, and pore-pore separation. Biophys J 67: 42-56

Charpentier KP, Wolf F, Noble L, Winn B, Resnick M, Dupuy DE 2010: Irreversible electroporation of the pancreas in swine: a pilot study. HPB (Oxford) 12: 348-351

Lee EW, Loh CT, Kee ST 2007: Imaging guided percutaneous irreversible electroporation: ultrasound and immunohistological correlation. Technol Cancer Res Treat 6: 287-293

Li W, Fan Q, Ji Z, Qiu X, Li Z 2011: The effects of irreversible electroporation (IRE) on nerves. PLoS One 6: 1-7

Li X, Xu K, Li W, Qiu X, Ma B, Fan Q, Li Z 2012: Immunologic response to tumor ablation with irreversible electroporation. PLoS One 7: 1-7

Mali B, Jarm T, Corovic S, Paulin-Kosir MS, Cemazar M, Sersa G, Miklavcic D 2008: The effect of electroporation pulses on functioning of the heart. Med Biol Eng Comput 46: 745-757

Maor E, Ivorra A, Leor J, Rubinsky B 2007: The effect of irreversible electroporation on blood vessels. Technol Cancer Res Treat 6: 307- 312

Martin RC, Schwartz E, Adams J, Farah I, Derhake BM 2015: Intra - operative Anesthesia Management in Patients Undergoing Surgical Irreversible Electroporation of the Pancreas, Liver, Kidney, and Retroperitoneal Tumors. Anesth Pain Med 5: 1-8

Martin RC II. 2015: Use of irreversible electroporation in unresectable pancreatic cancer. Hepatobiliary Surg Nutr 4: 211-215

Martin RC II, McFarland K, Ellis S, Velanovich V 2013: Irreversible electroporation in locally advanced pancreatic cancer: potential improved overall survival. Ann Surg Oncol 20: 443-449

Månsson C, Nilsson A, Karlson BM 2014: Severe complications with irreversible electroporation of the pancreas in the presence of a metallic stent: a warning of a procedure that never should be performed. Acta Radiol Short Rep 3: 1-3

Philips P, Hays D, Martin RC 2013: Irreversible electroporation ablation (IRE) of unresectable soft tissue tumors: learning curve evaluation in the first 150 patients treated. PLoS One 8: $1-9$

Philips P, Li Y, Li S, St Hill CR, Martin RC. 2015: Efficacy of irreversible electroporation in human pancreatic adenocarcinoma: advanced murine model. Mol Ther Methods Clin Dev 2: 1-7

Rubinsky B, Onik G, Mikus P 2007: Irreversible electroporation: a new ablation modality - clinical implications. Technol Cancer Res Treat 6: 37-48

Silk M, Tahour D, Srimathveeravalli G, Solomon SB, Thornton RH 2014: The State of Irreversible Electroporation in Interventional Oncology. Semin Intervent Radiol 31: 111-117

Teissie J 2014: Electropermeabilization of the cell membrane. Methods Mol Biol 1121: 25-46

Weaver JC 1995: Electroporation theory. Concepts and mechanisms. Methods Mol Biol 47: 1-26

Yao C, Guo F, Li C, Sun C 2013: Gene transfer and drug delivery with electric pulse generators. Curr Drug Metab 14: $319-323$ 
Plate I

Svatoň R. et al.: Selective effect ... pp. 133-137

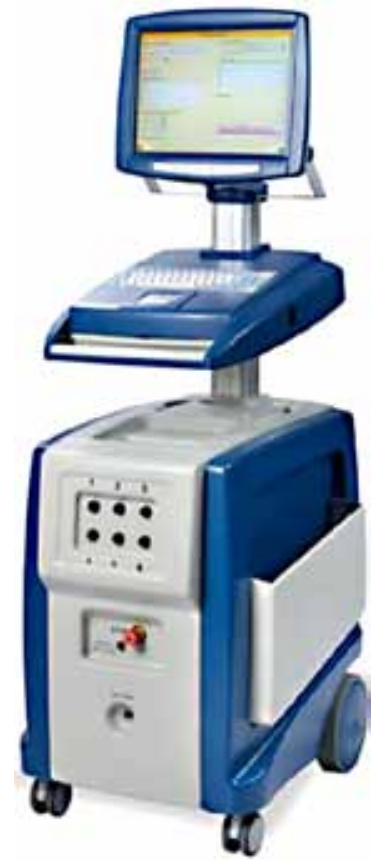

Fig. 1. NanoKnife ${ }^{\circledR}$

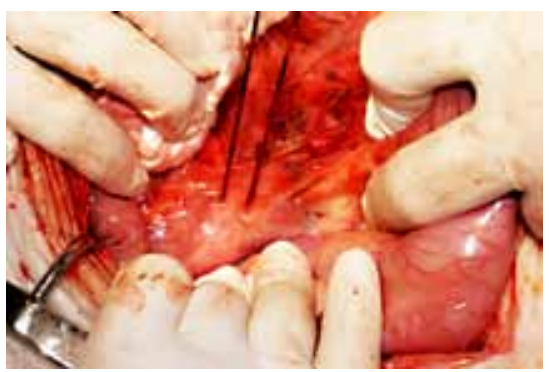

Fig. 2. Electrodes in the duodenal lobe of pancreas (*blood-vessel between electrodes)

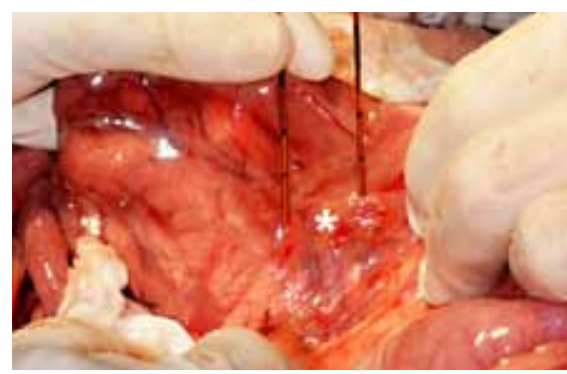

Fig. 3. Electrodes in the splenic lobe of pancreas 


\section{Subject I}

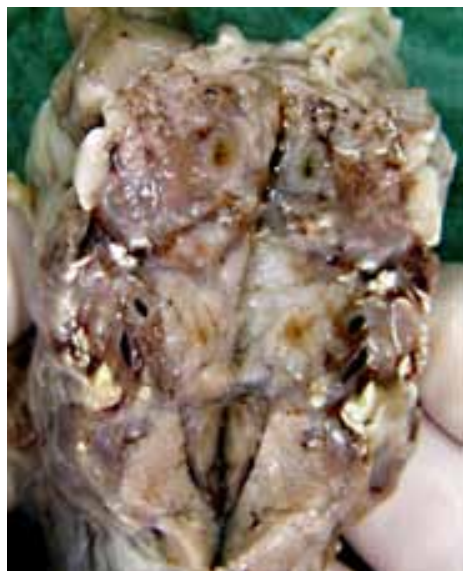

Fig. 4a. The duodenal lobe $(500 \mathrm{~V} / \mathrm{cm})$

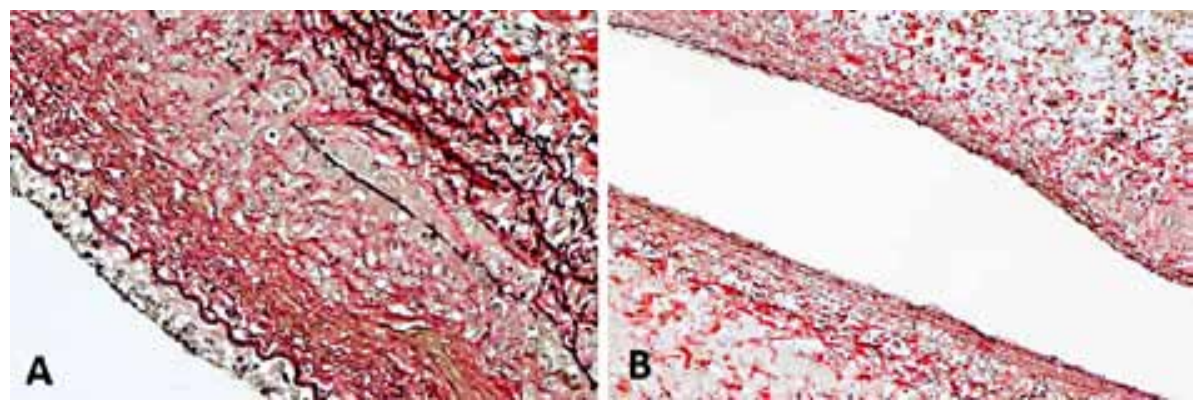

Fig. 4b. A - The artery $(500 \mathrm{~V} / \mathrm{cm}$, magnification $\times 100$, Sirius red elastic staining): preserved endothelium, clearly visible elastic lamina, muscular wall without any major regressive changes, without fibrinoid changes. Lumen without thrombosis. B - The vein $(500 \mathrm{~V} / \mathrm{cm}$, magnification $\times 40$, Sirius red elastic staining): preserved endothelium, wall without fibrinoid changes and without lumen thrombosis.
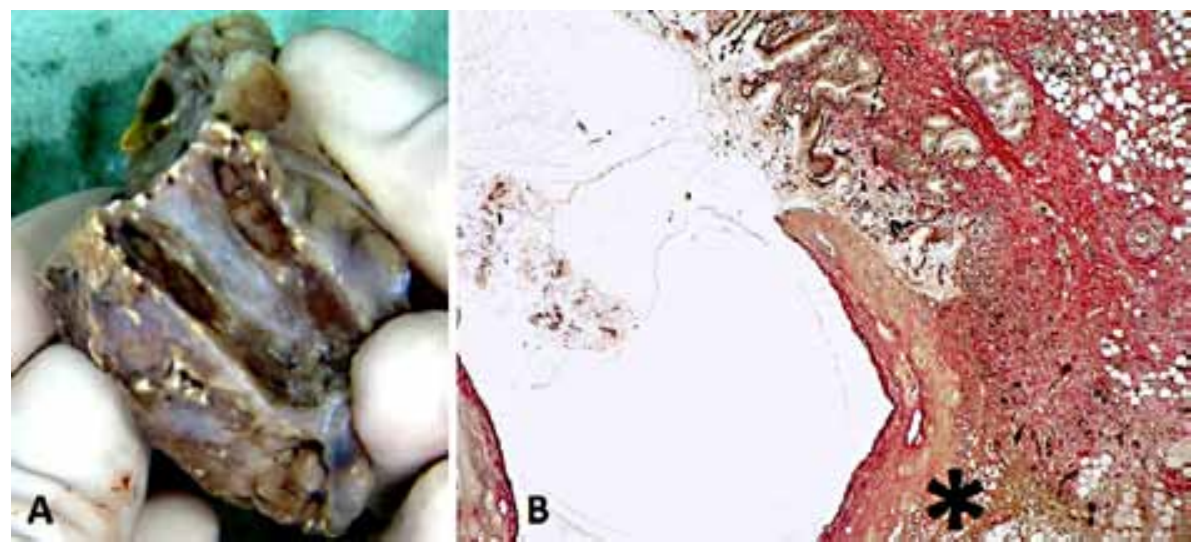

Fig. 5. A - The splenic lobe $(500 \mathrm{~V} / \mathrm{cm})$. B - The pancreatic duct with regressive changes in the wall $(500$ $\mathrm{V} / \mathrm{cm}$, magnification $\times 40$, Sirius red elastic staining) 


\section{Subject II}

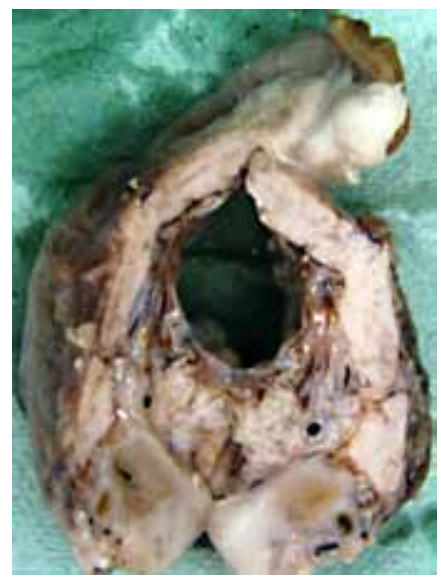

Fig 6a. The duodenal lobe $(750 \mathrm{~V} / \mathrm{cm})$

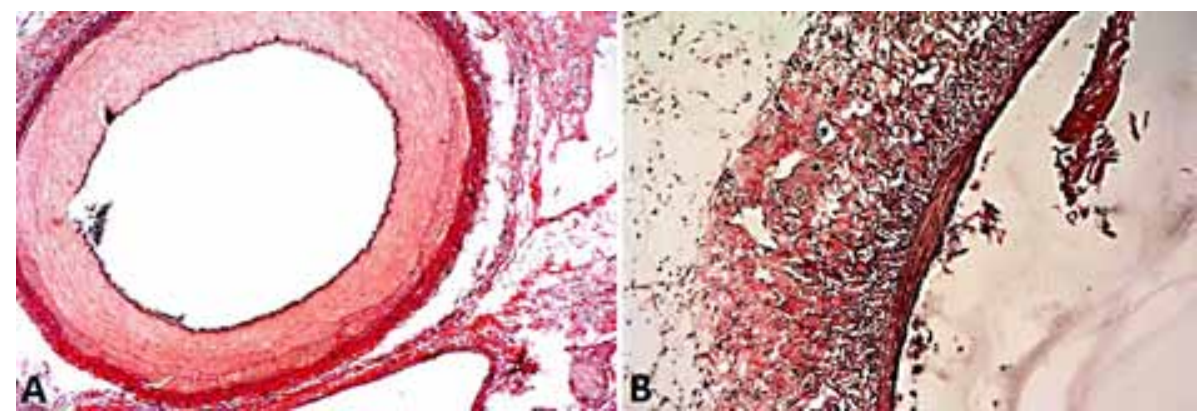

Fig. $6 \mathrm{~b}$. A - The artery $(750 \mathrm{~V} / \mathrm{cm}$, magnification $\times 40$, Sirius red elastic staining): no regressive changes, the intima with endothelium, well visible elastic lamina, without signs of necrosis, without thrombosis. B The vein $(750 \mathrm{~V} / \mathrm{cm}$, magnification $\times 100$, Sirius red elastic staining): slight alteration of the wall, without necrosis, without lumen thrombosis
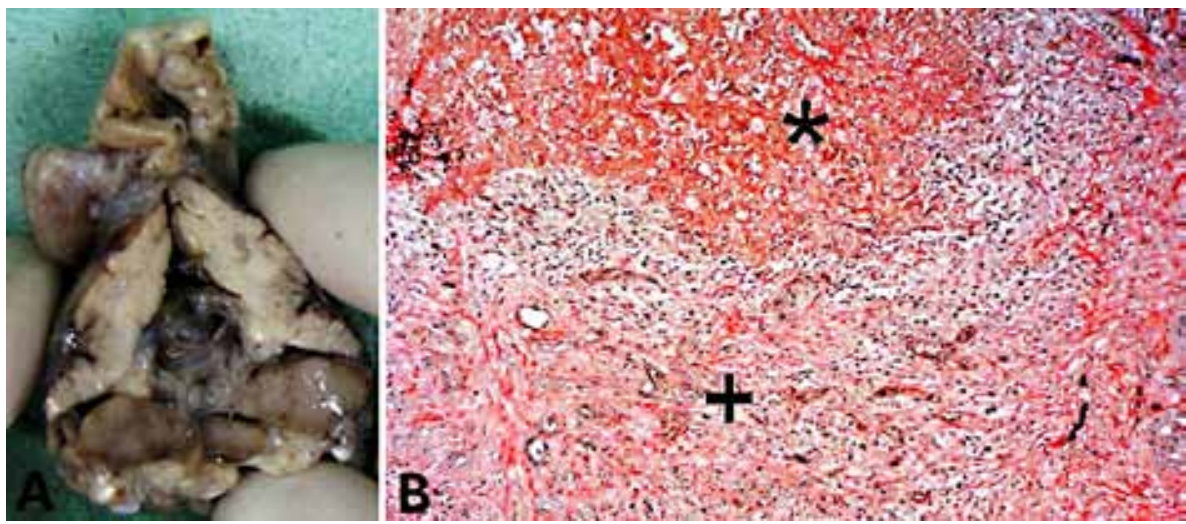

Fig. 7. A - The splenic lobe $(750 \mathrm{~V} / \mathrm{cm}) . \mathrm{B}-$ Necrosis $*$ with reparative reaction around $+(750 \mathrm{~V} / \mathrm{cm}$ magnification $\times 100$, Sirius red elastic staining) 


\section{Subject III}

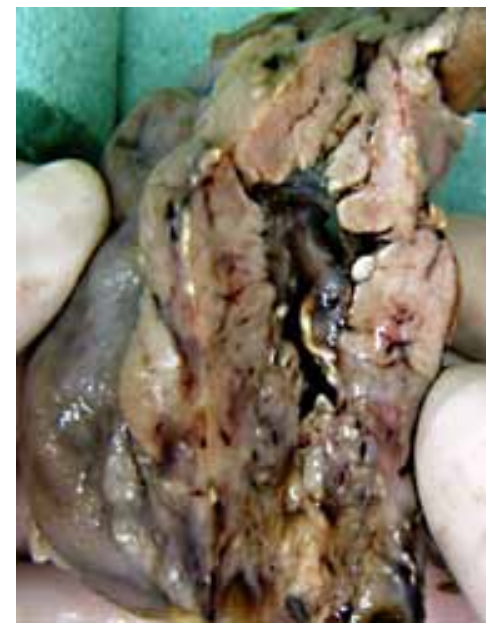

Fig. 8a. The duodenal lobe $(1,000 \mathrm{~V} / \mathrm{cm})$

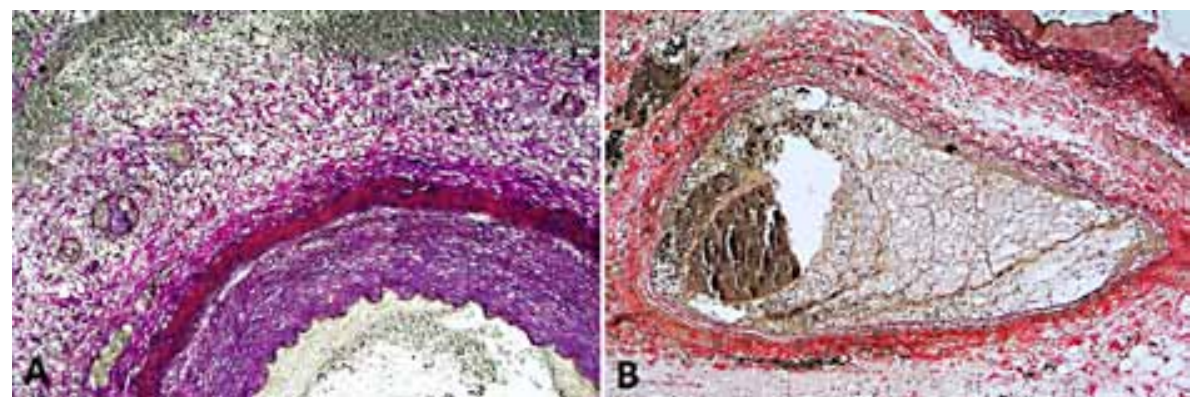

Fig. $8 \mathrm{~b}$. A - The artery $(1,000 \mathrm{~V} / \mathrm{cm}$, magnification $\times 100$, Acid fuchsin orange staining): preserved endothelium with the elastic laminas, sections of regressive changes in the outer half of the wall, without transmural necrosis, without thrombosis. B - The vein $(1,000 \mathrm{~V} / \mathrm{cm}$, magnification $\times 100$, Sirius red elastic staining): mild regressive changes of the wall with disruption of the elastic lamina, without transmural necrosis, lumen partially thrombosed.
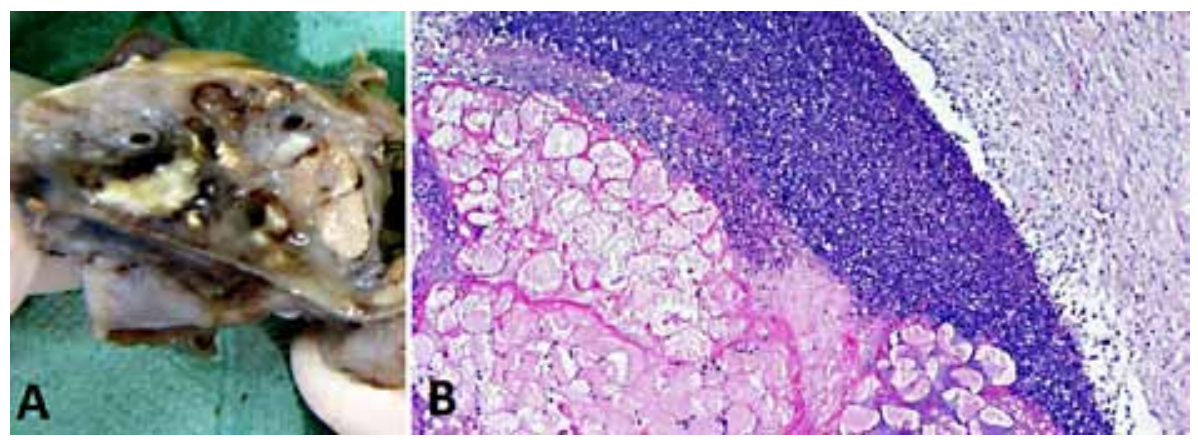

Fig. 9. A - The splenic lobe $(1,000 \mathrm{~V} / \mathrm{cm})$. B - Necrosis of pancreatic tissue $(1,000 \mathrm{~V} / \mathrm{cm}$, magnification $\times 100$, periodic acid-shiff staining) 


\section{Subject IV}

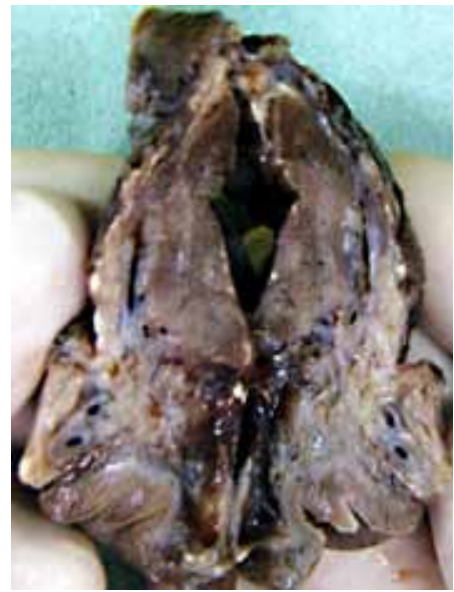

Fig. 10a. The duodenal lobe $(1,250 \mathrm{~V} / \mathrm{cm})$

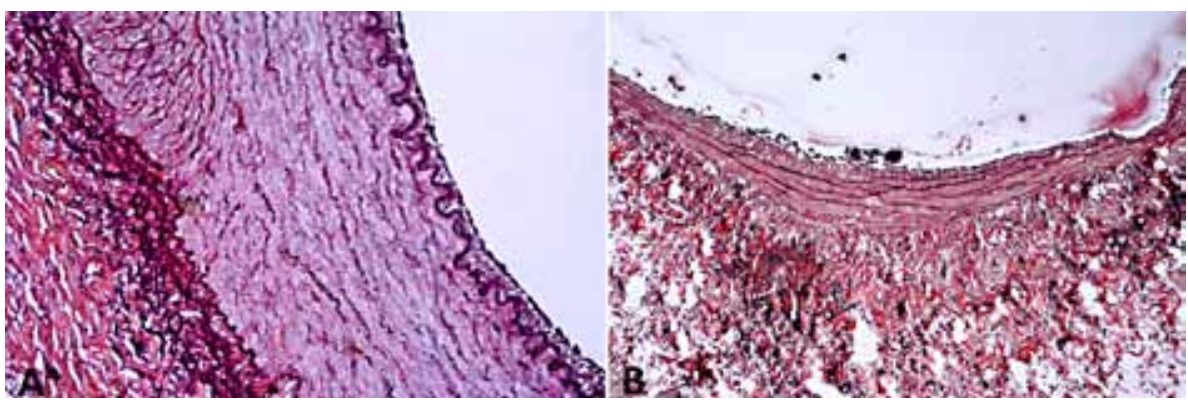

Fig 10b. A - The artery $(1,250 \mathrm{~V} / \mathrm{cm}$, magnification $\times 200$, Sirius red elastic staining) without significant changes. B - The vein $(1,250 \mathrm{~V} / \mathrm{cm}$, magnification $\times 100$, Sirius red elastic staining) with mild regressive changes in the outer half of the wall, without transmural necrosis, endothelium present without thrombosis
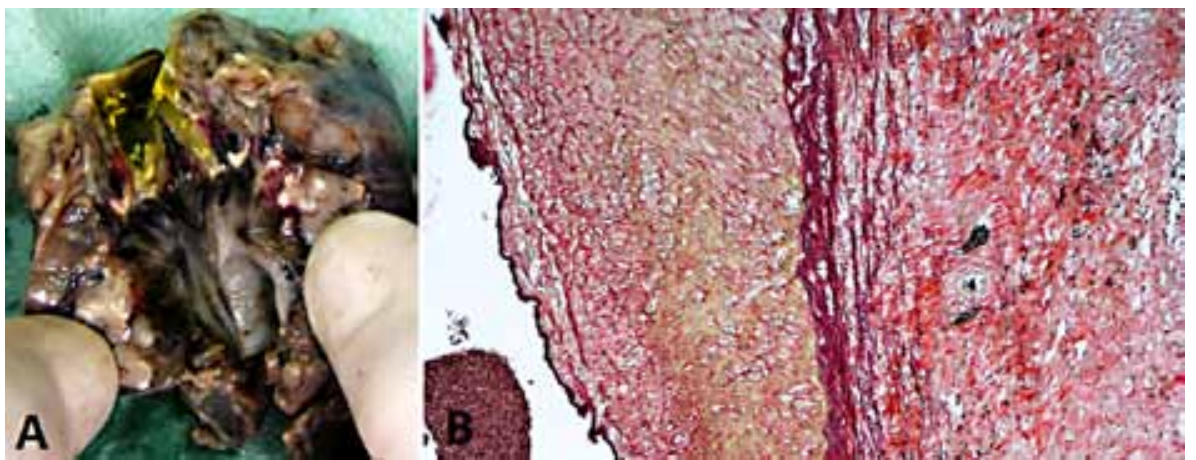

Fig. 11. A - The splenic lobe $(1,250 \mathrm{~V} / \mathrm{cm})$. B - Necrosis of the pancreatic tissue $(1,250 \mathrm{~V} / \mathrm{cm}$, magnification $\times 100$, Sirius red elastic staining) 


\section{Subject V}

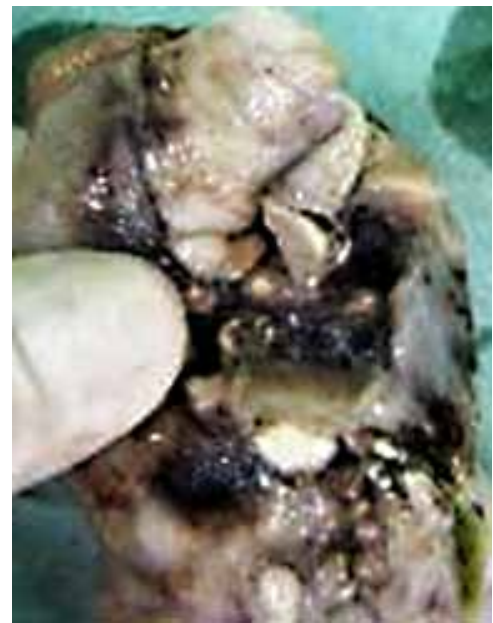

Fig. 12a. The duodenal lobe $(1,500 \mathrm{~V} / \mathrm{cm})$
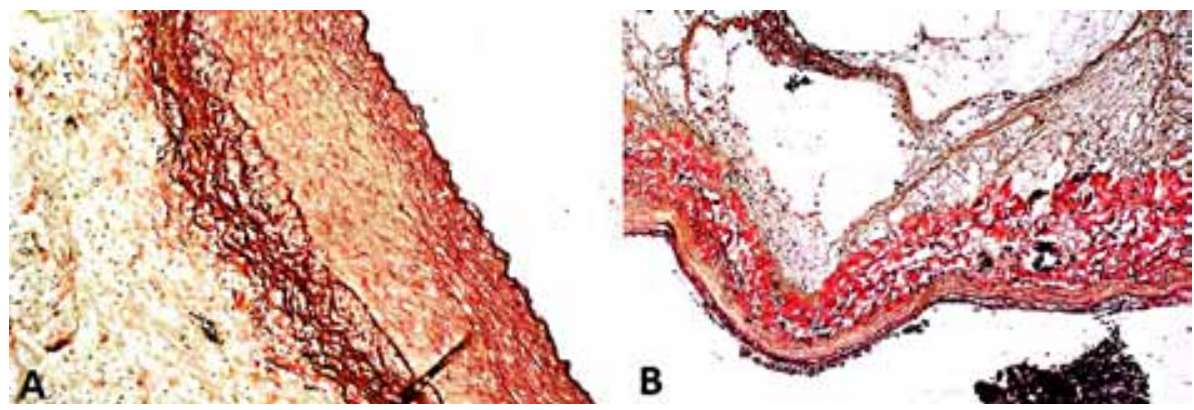

Fig. 12b. A - The artery $(1,500 \mathrm{~V} / \mathrm{cm}$, magnification $\times 100$, Sirius red elastic staining): without significant regressive change, without transmural necrosis, elastic lamina clear, visible endothelium; B - The vein $(1,500 \mathrm{~V} / \mathrm{cm}$, magnification $\times 100$, Sirius red elastic staining): mild regressive changes in the outer half of the wall without transmural necrosis; endothelium recognizable; small thrombus in the lumen.
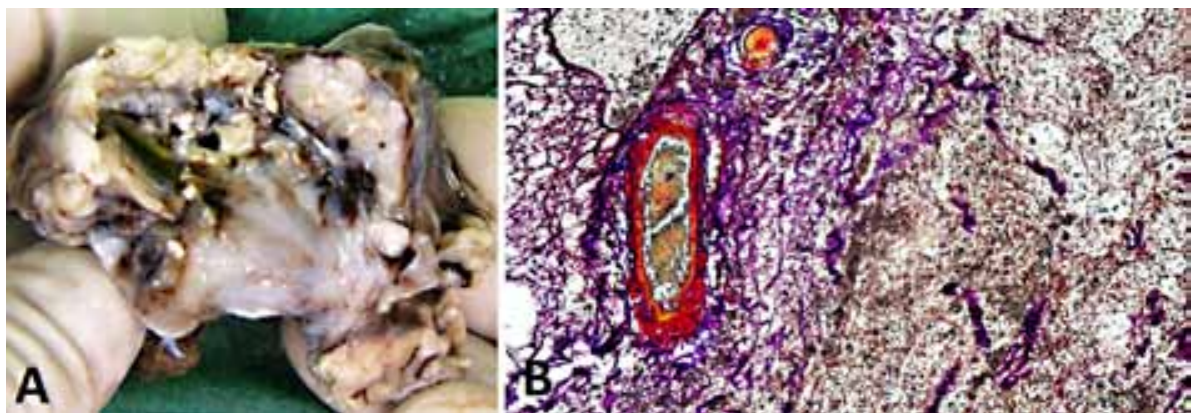

Fig. 13. A - The splenic lobe $(1,500 \mathrm{~V} / \mathrm{cm}) . \mathrm{B}$ - Necrosis of the pancreatic tissue, in this terrain regressive changes smaller muscular arteries $(1,500 \mathrm{~V} / \mathrm{cm}$, magnification $\times 200$, Acid fuchsin orange staining) 


\section{Subject VI}

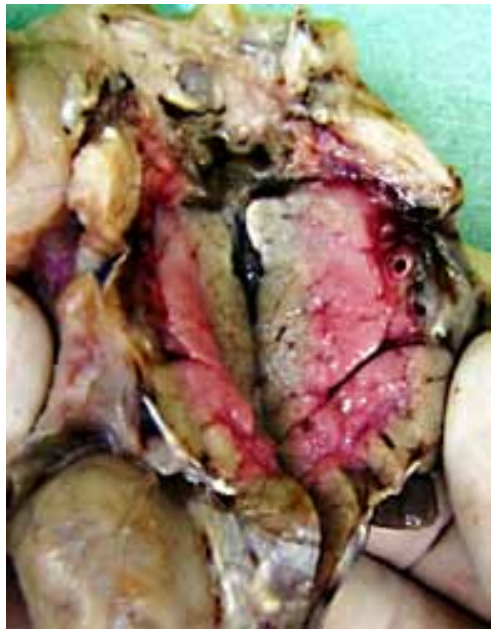

Fig 14a. The duodenal lobe $(1,750 \mathrm{~V} / \mathrm{cm})$

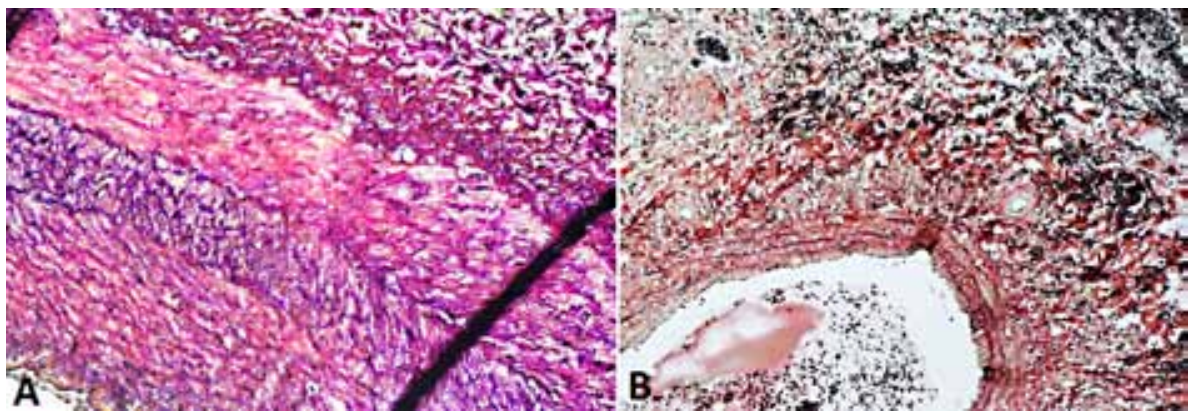

Fig. 14b. Sections with regressive changes on the outer half of the artery (A, magnification $\times 200$, Acid fuchsin orange staining) and the vein $(\mathrm{B}$, magnification $\times 100$, Sirius red elastic staining), without transmural necrosis, endothelium maintained $(1,750 \mathrm{~V} / \mathrm{cm})$
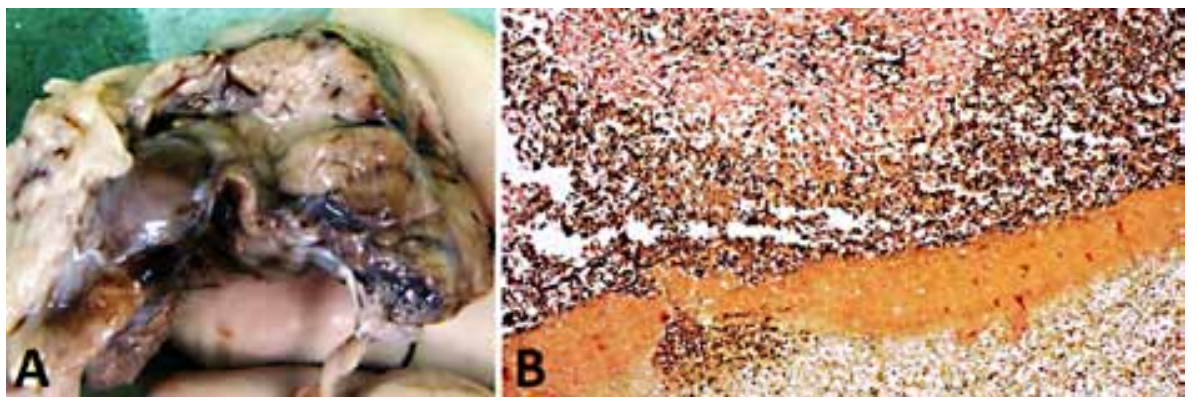

Fig. 15. A - The splenic lobe $(1,750 \mathrm{~V} / \mathrm{cm})$. B - Necrosis of pancreatic tissue $(1,750 \mathrm{~V} / \mathrm{cm}$, magnification $\times 100$, Sirius red elastic staining) 